\title{
iᄃETL
}

International Conference on Research in Education, Teaching and Learning

Paris, France| November 2-4, 2018

\section{The Impact of Foundation Design Studio Courses on Interior Architecture Program: CFAD Model}

\author{
Abdulsamad Alkhalidi
}

\begin{abstract}
Many parents and students in the UAE and Middle East give preference to Architecture and Interior Design career as a stable and growth-oriented avenue. The rapid urbanization in the region and many ambitious plans (such as Vision 2021 and Vision 2030) for further development in the building and construction sector evokes such aspirations. In response, many American and British Universities have set-up institutions providing modern educational avenues at par with those in the countries of their origin. The core of education in Architecture and Interior Design is the Design Studio. The qualifying criteria to advanced courses require the students to go through a foundational course. Such rigorous entry procedure is expected to prepare students for professional practice. However, employers complain of lack of quality and preparedness in new recruits. In addition, students lack the skills to incorporate factors such as sustainability, changes in the new material available, and region-specific condition when designing projects.

This paper conducted a survey of Interior Design students in the Region to assess the areas of difficulties and specific domains of instructional framework from their perspective. The author of this work believes that revisiting earlier visions of masters in the Design Studio domain and then taking cognizance of improvements thereto sought in learning-teaching methodology through research studies in recent times would help devise mitigation process of Studio Design teaching process. The results show that the overall satisfaction level of students in three consecutive batches is low, and that they seem to seek improvement in some areas. This is an important inference, because, as recipients of the teaching deliverance, students are the most important stakeholders that can provide meaningful feedback. However, the results also expose some inconsistencies regarding overall satisfaction level, though over the years some improvement is evident regarding freedom to express creativity.
\end{abstract}

Keywords: effective learning, sustainability, design studio, experiential processes Themes. 